\section{Geometrie im Gespräch}

\author{
Erhard Taverna
}
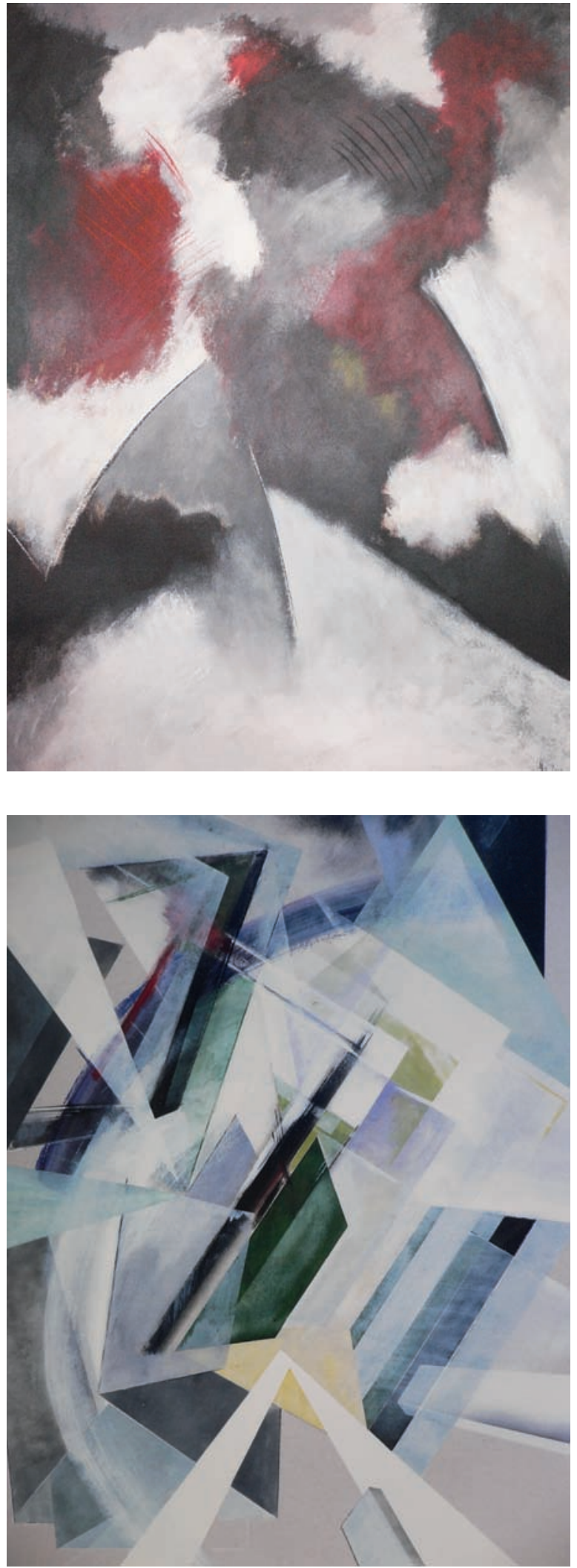

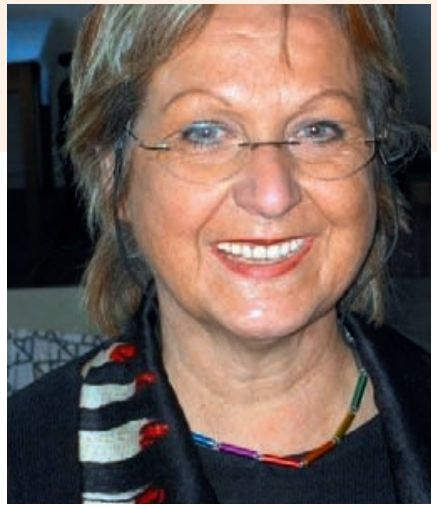

Wer die Redaktionsräume des Schweizerischen Ärzteverlages in Muttenz betritt, kann sie nicht übersehen, die grossformatigen Bilder an den weissen Wänden der langen Korridore, verteilt über die obersten Stockwerke des Gebäudes der Druckerei Schwabe. Warme Rottöne kontrastieren mit schwarzen und weissen Abstraktionen, totemhafte Figurengruppen ziehen den eiligen Besucher in ihren Bann und geometrische Kompositionen befördern den Betrachter in eine flaschengrüne, fast bedrohliche Tiefe.

In regelmässigen Abständen wechselt die Künstlerin und Redaktionsassistentin der Schweizerischen Ärztezeitung Margrit Neff (mneff@emh.ch) ihre Bilder aus. Geboren 1947, hat sie erst alle Schulhefte vollgemalt und als Aupair-Mädchen Schaufenster dekoriert. Sie durfte durch ihren weltlich gesinnten Pfarreronkel an Ausstellungen teilhaben und schärfte ihren Blick für die Natur auf seinen ausgedehnten Krankenbesuchen in den Urner Bergen. Abendkurse an der Gewerbeschule und Unterricht im Sommercasino Basel waren die üblichen Stationen einer ausdauernden Autodidaktin, die, statt wunschgemäss Grafikerin zu lernen, eine Handelsschule vorziehen musste. Die Anstellung als Direktionssekretärin eines kunstsinnigen Chefs mit einer privaten Gemäldesammlung erwies sich als Glücksfall, erst recht die langjährige Schulung durch den Allschwiler Kunstmaler Leo Remond.

In nächster Nähe ihres Büros steht Margrit Neff ein grosser, heller Raum im Areal der Drukkerei zur Verfügung. Dort malt sie mit Acryl, Kohle und Pastell direkt auf Karton oder Pavatex, seltener auf Leinwand. Hinter der Staffelei lehnen weitere Bilder an der Wand. Die letzten Ausstellungen liegen Jahre zurück. Die Einladung, in grossem Rahmen zusammen mit einem lokal bekannten Bildhauer auszustellen, hat Frau Neff in letzter Minute ausgeschlagen, denn öffentliche Auftritte liegen ihr nicht. Noch gehen die Bilder unter der Hand weg, ein Tip unter Kennern. Vielleicht wird sich das ändern, wenn die Künstlerin 

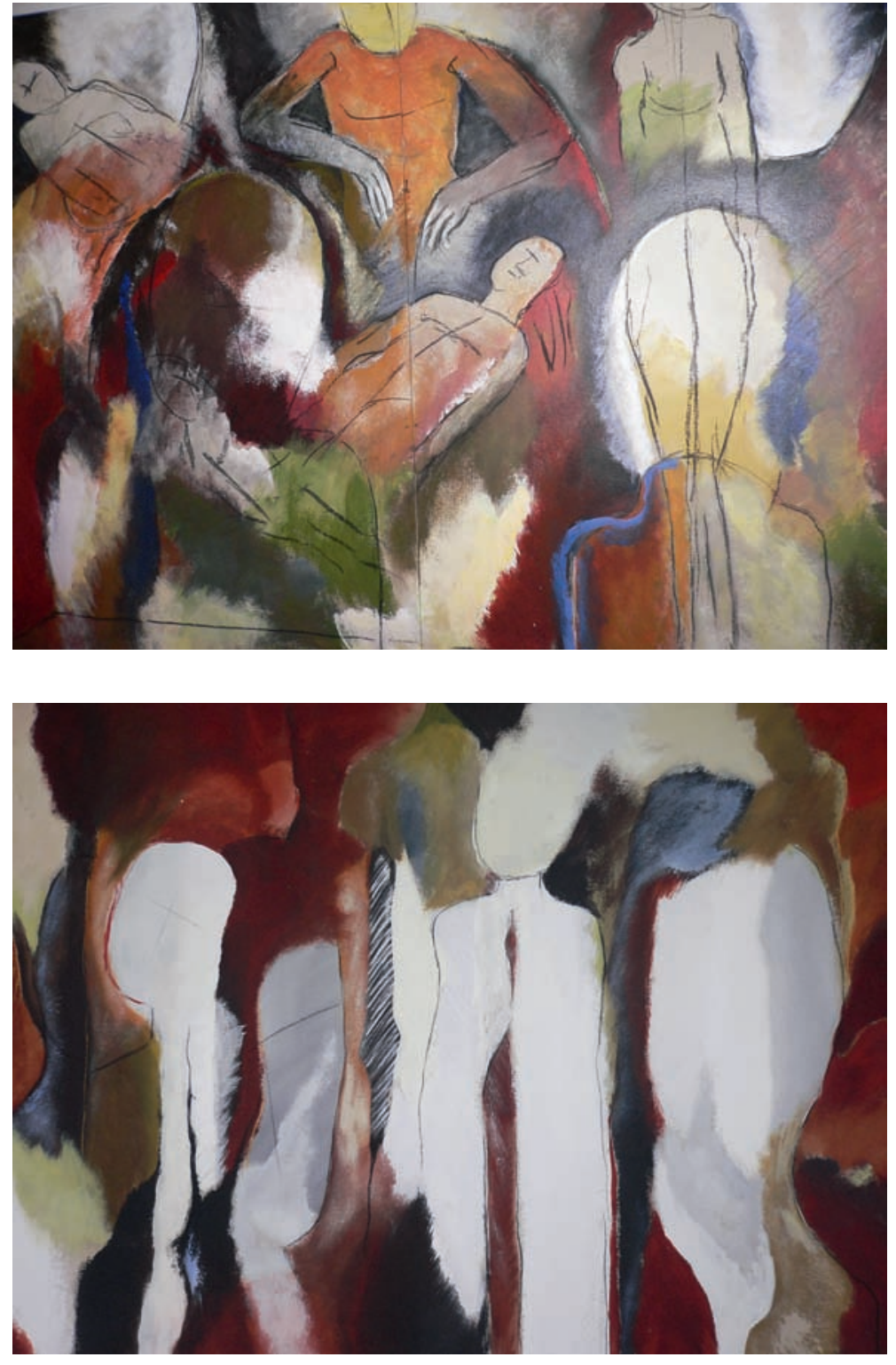

altershalber ihren Bürosessel räumt. Wünschbar wäre die verdiente Musse für das Eigene, ein «Egotrip» mit Reisen, Skizzieren und ausgiebigem Malen - und vielleicht doch Ausstellungen? Ein Stapel Aktzeichnungen im Atelier lässt auf weitere Bearbeitungen hoffen. Sie arbeite auf zwei verschiedene Arten, erklärt sie, diszipliniert oder frei, streng kompositorisch-geometrisch oder wolkig-weich, fliessend und rund. Man glaubt ihr sofort, dass sie gerne Bühnenbilder entwerfen würde. Davon zeugen die architektonische Raumstruktur und die bühnenhafte Choreographie vieler Werke.

Gut möglich, dass der frühere Klavierunterricht oder das ausgeübte Töpferhandwerk den Stil der Bilder bereichern. Hinter jeder reifen Kunst stecken viele Geschichten. Der erste Sohn, heute Berufsmusiker, ist mit einer Spina bifida geboren und brauchte lange die ganze Unterstützung der Eltern. Und auch sonst blieb die Familie von gesundheitlichen Schicksalsschlägen nicht verschont. Margrit Neff hat allen Widrigkeiten des Alltags zum Trotz für ihre Erfahrungen eine persönliche malerische Sprache gefunden. Was sie mit Formen und Farben sichtbar macht, verführt zum Gespräch, weil eine raumgreifende Klarheit jedes Geschwätz eliminiert hat. Man könnte auch sagen, dass zwei Sphären im Dialog ihr Werk durchdringen: das Harte mit glasklaren, scharfkantigen, fast schneidenden, kristallinen Gebilden und das Weiche mit warmen, bergenden und auflösenden Konturen.

Wenn «unsere» Redaktionsassistentin nicht gerade E-Mails beantwortet, Artikel aufnimmt oder sich um Stellenvermittlung, Internetportal und Datenbank kümmert, dann malt sie (fast) unentdeckt ein neues Bild. 